\title{
A Prospective Study of Pravastatin in the Elderly at Risk (PROSPER): Screening Experience and Baseline Characteristics
}

\author{
Ian Ford*1, Gerard Jan Blauw2, Michael B Murphy3 ${ }^{3}$, James Shepherd ${ }^{1}$, \\ Stuart M Cobbe ${ }^{1}$, Edward LEM Bollen ${ }^{2}$, Brendan M Buckley ${ }^{3}$, J \\ Wouter Jukema2, Michael Hyland ${ }^{3}$, Allan Gaw ${ }^{1}$, A Margot Lagaay ${ }^{2}$, \\ Ivan J Perry ${ }^{3}$, Peter W Macfarlane ${ }^{1}$, John Norrie ${ }^{1}$, A Edo Meinders ${ }^{2}$, \\ Brian J Sweeney ${ }^{3}$, Chris J Packard1, Rudi GJ Westendorp2 ${ }^{2}$, Cillian Twomey ${ }^{3}$ \\ and David J Stott ${ }^{1}$ for the PROSPER Study Group
}

Address: ${ }^{1}$ University of Glasgow, Scotland, ${ }^{2}$ University of Leiden, The Netherlands and ${ }^{3}$ University of Cork, Ireland

E-mail: Ian Ford* - ian@stats.gla.ac.uk; Gerard Blauw - G.J.Blauw@lumc.nl; Michael B Murphy - mmurphy@medicine.ucc.ie; James Shepherd - jshepherd@gri-biochem.org.uk; Stuart M Cobbe - stuart.cobbe@clinmed.gla.ac.uk;

Edward LEM Bollen - e.l.e.m.bollen.neurology@lumc.nl; Brendan M Buckley - brenbuck@ucc.ie; J Wouter Jukema - J.W.Jukema@lumc.nl; Michael Hyland - michaelchyland@eircom.net; Allan Gaw - AllanGaw@compuserve.com; A Margot Lagaay - longarts@diac-leiden16.demon.nl; Ivan J Perry - i.perry@ucc.ie; Peter W Macfarlane - p.w.macfarlane@clinmed.gla.ac.uk; John Norrie - j.norrie@stats.gla.ac.uk; A

Edo Meinders - a.e.meinders@lumc.nl; Brian J Sweeney - bsweeney@eircom.net; Chris J Packard - chris.packard@clinmed.gla.ac.uk; Rudi GJ Westendorp - R.G.J.Westendorp@LUMC.nl; Cillian Twomey - twomeyc@SHB.IE; David J Stott - d.j.stott@clinmed.gla.ac.uk; the PROSPER Study Group - ian@stats.gla.ac.uk

${ }^{*}$ Corresponding author

Published: 20 May 2002

Current Controlled Trials in Cardiovascular Medicine 2002, 3:8

This article is available from: http://crm.controlled-trials.com/content/3/I/8

(C) 2002 Ford et al; licensee BioMed Central Ltd. Verbatim copying and redistribution of this article are permitted in any medium for any purpose, provided this notice is preserved along with the article's original URL.

Keywords: clinical trial, elderly, pravastatin, baseline characteristics
Received: 21 January 2002

Accepted: 20 May 2002 


\section{Introduction}

Previous trials of HMG Co-A reductase inhibitors [1-5] have focused primarily on subjects under the age of 70 years. The PROspective Study of Pravastatin in the Elderly at Risk (PROSPER) is a randomised, double blind, placebo-controlled trial to test the hypothesis that treatment with pravastatin will diminish the risk of subsequent major vascular events in a cohort of high-risk elderly individuals with a wide range of cholesterol levels. The primary endpoint is the composite outcome of coronary heart disease death, non-fatal myocardial infarction, and fatal or non-fatal stroke. This report describes the outcome of study recruitment, the baseline characteristics of the randomised subjects, and contrasts the randomised subjects with the total population of screenees.

\section{Methods}

\section{Overview of study design and data acquisition}

The study has been described in detail elsewhere [6]. Briefly, PROSPER is designed to examine the benefits of pravastatin (40 mg per day) versus placebo in 70-82 year old men and women with either pre-existing vascular disease or elevated risk of such disease due to smoking, hypertension, or diabetes. Age-eligible individuals in the primary care setting were invited to attend an initial screening visit (S1) conducted by a study nurse, at which consent for the screening process, a brief medical history, and vital signs were recorded, and dietary and appropriate health advice given. Data recorded included standard risk factors such as age, sex, blood pressure, heart rate, body mass index, history of hypertension, diabetes, smoking, and vascular disease. At subsequent visits prior to randomisation, these data were recorded again, along with alcohol consumption (measured in units/week, with one unit being equivalent to one glass of wine, one half pint of beer or one standard measure of spirits), current medication use, and details of previous major illnesses and ongoing chronic conditions. In Scotland and Ireland, the subjects were invited in an unselected manner. In the Netherlands, however, subjects were pre-selected on the basis of possession of previously known cardiovascular risk factors. Subjects who continued to be eligible after screening were invited to a second screening visit (S2), at which a more detailed medical history was taken and a fasting venous blood sample drawn for biochemical and hematological checks and lipoprotein quantification. If, on the basis of their blood results, subjects were still eligible (plasma total cholesterol $4.0-9.0 \mathrm{mmol} / \mathrm{l}[155-350 \mathrm{mg} / \mathrm{dl}]$, triglycerides $\leq 6.0 \mathrm{mmol} / \mathrm{l}[530 \mathrm{mg} / \mathrm{dl}])$, they were invited to attend a third screening (or first enrollment) visit (A1), where another blood sample was taken, and the MiniMental State Examination [MMSE] and various psychometric tests (Picture-Word Learning Test, Stroop Word Colour Test, Letter Digit Coding Test) were administered. Subject to satisfactory placebo run-in compliance $(\geq 75 \%$ but less than 120\%), ECG reading, and MMSE score > 24, subjects then attended a fourth screening (second enrollment) visit (A2), at which time the psychometric tests were re-administered as well as "activities of daily living" questionnaires (modified Barthel and Instrumental Activities of Daily Living). Consenting and still-eligible subjects were then randomised to study treatment. All patients were expected to be sufficiently mobile to attend the study randomisation visit at their general practitioner's office. Further details of the inclusion and exclusion characteristics are given in the study design paper [6]. The target sample size was 5,500 subjects (3,000 women and 2,500 men) split approximately evenly between those with and without a history of vascular disease.

All data were processed at the study data centre in The Robertson Centre for Biostatistics, University of Glasgow, Scotland. The fasting blood samples taken at visits S2 and A1 provided full lipoprotein profiles obtained in the Centre for Disease Control - certified central lipoprotein laboratory in Glasgow Royal Infirmary, Glasgow, Scotland. At visit A1, a 12-lead ECG was recorded and automatically Minnesota coded after electronic transmission to the central ECG laboratory in the University of Glasgow Department of Medical Cardiology at the Royal Infirmary, Glasgow, Scotland [7].

\section{Statistical Methods}

Most of the analyses presented here are descriptive in nature. Continuous variables are summarised as mean \pm SD. Data for categorical variables are presented as counts and percentages of the total group of randomised or screened subjects or subgroups as appropriate. Summary statistics for plasma triglycerides are presented untransformed.

\begin{tabular}{|c|c|c|c|c|}
\hline & Scotland & Ireland & $\begin{array}{l}\text { Nether- } \\
\text { lands }\end{array}$ & Total \\
\hline Visit SI & 11770 & 10157 & 1843 & 23770 \\
\hline Visit S2 & $4324(37 \%)$ & 4090 (40\%) & I 373 (74\%) & 9787 (42\%) \\
\hline Visit AI & $3183(27 \%)$ & 3021 (30\%) & 1249 (68\%) & $7453(31 \%)$ \\
\hline Visit A2 & $2689(23 \%)$ & $2358(23 \%)$ & $1114(60 \%)$ & 6161 (26\%) \\
\hline Randomised & $2520(21 \%)$ & $2184(22 \%)$ & 1100 (60\%) & $5804(24 \%)$ \\
\hline
\end{tabular}


Table 2: Comparison of all screenees $(n=23770)$ with randomised subjects $(n=5804)$ on the basis of data recorded at the initial screening visit (SI). Data are presented for Scotland, Ireland and for The Netherlands, and for men and women. Data are presented as mean (SD) for continuous variables and as \% of column total for categorical variables.

\begin{tabular}{|c|c|c|c|c|c|c|c|c|c|c|c|c|}
\hline & \multicolumn{4}{|c|}{ Scotland } & \multicolumn{4}{|c|}{ Ireland } & \multicolumn{4}{|c|}{ Netherlands } \\
\hline & \multicolumn{2}{|c|}{ Men } & \multicolumn{2}{|c|}{ Women } & \multicolumn{2}{|c|}{ Men } & \multicolumn{2}{|c|}{ Women } & \multicolumn{2}{|c|}{ Men } & \multicolumn{2}{|c|}{ Women } \\
\hline & $\begin{array}{c}\text { All } \\
\text { Screenees }\end{array}$ & $\begin{array}{l}\text { Randomised } \\
\text { Subjects }\end{array}$ & $\begin{array}{c}\text { All } \\
\text { Screenees }\end{array}$ & $\begin{array}{l}\text { Randomised } \\
\text { Subjects }\end{array}$ & $\begin{array}{c}\text { All } \\
\text { Screenees }\end{array}$ & $\begin{array}{l}\text { Randomised } \\
\text { Subjects }\end{array}$ & $\begin{array}{c}\text { All } \\
\text { Screenees }\end{array}$ & $\begin{array}{l}\text { Randomised } \\
\text { Subjects }\end{array}$ & $\begin{array}{c}\text { All } \\
\text { Screenees }\end{array}$ & $\begin{array}{l}\text { Randomised } \\
\text { Subjects }\end{array}$ & $\begin{array}{c}\text { All } \\
\text { Screenees }\end{array}$ & $\begin{array}{l}\text { Randomised } \\
\text { Subjects }\end{array}$ \\
\hline $\begin{array}{l}\text { Number of } \\
\text { subjects }\end{array}$ & 5117 & 1237 & 6653 & 1283 & 4528 & 988 & 5629 & 1196 & 972 & 581 & 871 & 519 \\
\hline \multicolumn{13}{|l|}{$\begin{array}{l}\text { Continuous } \\
\text { variables }\end{array}$} \\
\hline Age (years) & $74.9(3.4)$ & 74.7 (3.2) & $75.4(3.5)$ & $75.4(3.5)$ & $75.3(3.4)$ & 74.9 (3.3) & 75.7 (3.4) & $75.4(3.3)$ & $74.7(3.3)$ & 74.5 (3.3) & $75.3(3.3)$ & $75.3(3.3)$ \\
\hline $\mathrm{SBP}(\mathrm{mmHg})$ & $156(24)$ & $158(23)$ & $154(23)$ & $155(23)$ & $158(24)$ & $160(24)$ & $155(24)$ & $158(23)$ & $160(23)$ & $162(23)$ & $159(23)$ & $160(23)$ \\
\hline $\mathrm{DBP}(\mathrm{mmHg})$ & $85(12)$ & $84(12)$ & $84(12)$ & $84(12)$ & $85(12)$ & $85(13)$ & $84(12)$ & $85(11)$ & $87(12)$ & $88(I I)$ & 87 (II) & 87 (II) \\
\hline $\begin{array}{l}\text { Heart Rate } \\
\text { (b.p.m.) }\end{array}$ & $72(13)$ & $70(13)$ & $75(12)$ & $73(13)$ & $73(13)$ & $71(13)$ & $76(12)$ & $74(12)$ & $73(13)$ & $72(12)$ & $76(12)$ & $75(12)$ \\
\hline BMI $\left(\mathrm{kg} / \mathrm{m}^{2}\right)$ & $26.2(3.7)$ & $26.4(3.7)$ & $26.2(4.6)$ & $27.0(4.7)$ & $26.6(4.0)$ & $26.8(3.8)$ & $26.2(4.7)$ & $27.0(4.8)$ & $25.8(3.1)$ & $26.0(3.1)$ & $26.7(4.1)$ & $27.2(4.2)$ \\
\hline \multicolumn{13}{|l|}{$\begin{array}{l}\text { Categorical } \\
\text { variables }\end{array}$} \\
\hline \multicolumn{13}{|l|}{ Smoker: } \\
\hline Current & 21.3 & 32.5 & 16.2 & 24.4 & 22.4 & 34.5 & 14.5 & 20.4 & 27.1 & 31.7 & 14.5 & 16.0 \\
\hline Former & 54.9 & 48.4 & 32.6 & 32.3 & 52.7 & 45.5 & 27.6 & 24.8 & 65.4 & 61.3 & 30.0 & 27.2 \\
\hline Never & 23.8 & 19.1 & 51.2 & 43.3 & 24.8 & 20.0 & 57.9 & 54.8 & 7.5 & 7.0 & 55.6 & 56.8 \\
\hline Diabetic & 7.2 & 9.5 & 4.6 & 5.7 & 8.0 & 12.3 & 5.6 & 8.2 & 13.5 & 13.4 & 14.9 & 15.6 \\
\hline Hypertensive & 28 & 47 & 35 & 64 & 32 & 49 & 44 & 74 & 44 & 51 & 61 & 74 \\
\hline $\begin{array}{l}\text { Vascular } \\
\text { disease }\end{array}$ & 38 & 56 & 28 & 42 & 32 & 47 & 23 & 31 & 48 & 53 & 30 & 34 \\
\hline
\end{tabular}

\section{Results}

\section{Recruitment}

A summary of recruitment data is given in Table 1. In Scotland and Ireland, subjects were invited for screening without pre-selection, with 11,770 and 10,157 subjects attending for screening from each country, respectively. Of these, similar percentages attended visits S2, A1, and A2, and were eventually randomised (2,520 from Scotland and 2,184 from Ireland). In the Netherlands, only 1,843 subjects were screened, but due to the pre-screening, a much higher percentage was randomised, yielding 1,100 randomised subjects. Randomisation was completed between February, 1998 and May, 1999.

\section{Comparison of Randomised subjects with the population of screenees}

The 23,770 screenees are compared with the 5,804 randomised subjects in Table 2. Summary statistics are presented for each country and for men and women. Although there are some minor variations, the mean ages, blood pressures, heart rates, and body mass indices do not differ substantially across countries, genders, and between the screenees and randomised subject groups. Subjects were randomised on the basis of having a history of vascular disease, defined by physician-diagnosed stable angina or intermittent claudication, stroke, transient ischaemic attack, myocardial infarction, arterial surgery, or amputation for vascular disease (secondary prevention cohort), or having a history of hypertension, diabetes, or smoking in the absence of a history of vascular disease (primary prevention cohort). Hence, not surprisingly, these risk factors were more prevalent among the randomised subjects. A history of vascular disease was more common in men, a history of hypertension more common in women, and a history of diabetes more common in subjects randomised in the Netherlands. These differences are driven by study entry criteria and by differences in recruitment strategies as much as by differences in the underlying populations.

\section{Characteristics of the randomised subjects}

Key risk factors and baseline medications for randomised subjects are summarised in Table 3 . The average age ranged from 74.7-76.2 years among men and women in the primary and secondary prevention groups. Three thousand of the 5,804 randomised subjects were women and 3,239 were in the primary prevention cohort. In this elderly group of subjects, the systolic blood pressures were higher than has been seen in previous prevention trials, with average systolic blood pressures in the four subgroups ranging from $151.5-157.7 \mathrm{mmHg}$. In the primary prevention cohort, $45 \%$ of men and $25 \%$ of women were current smokers. The corresponding numbers were $21 \%$ and $15 \%$ in the secondary prevention group. Consump- 
Table 3: Risk factor distributions as measured prior to randomisation for men, women, high risk subjects with no history of vascular disease (Primary Prevention) and subjects with a history of vascular disease (Secondary Prevention). Data shown are mean (SD) for continuous variables and $\%$ of randomised subjects within each column for categorical variables.

\begin{tabular}{|c|c|c|c|c|}
\hline & \multicolumn{2}{|c|}{ Men } & \multicolumn{2}{|c|}{ Women } \\
\hline & Primary & Secondary & Primary & Secondary \\
\hline Subjects (\%) & $1345(23.2)$ & $1459(25.1)$ & $1894(32.6)$ & $1106(19.1)$ \\
\hline \multicolumn{5}{|l|}{ Continuous variables } \\
\hline Age (years) & $74.7(3.2)$ & $75.3(3.3)$ & $75.3(3.3)$ & $76.2(3.4)$ \\
\hline $\mathrm{SBP}(\mathrm{mmHg})$ & $157.7(21.7)$ & $152.8(22.2)$ & $155.8(21.3)$ & $151.5(21.8)$ \\
\hline $\mathrm{DBP}(\mathrm{mmHg})$ & $85.9(11.4)$ & $81.9(11.4)$ & 84.7 (II.2) & $82.1(11.5)$ \\
\hline Height $(\mathrm{cm})$ & $172.5(6.8)$ & $171.7(6.6)$ & $159.1(6.7)$ & I58.4 (6.6) \\
\hline Weight (kg) & $79.1(12.3)$ & $78.4(11.6)$ & $68.9(12.9)$ & $67.4(12.1)$ \\
\hline BMI $\left(\mathrm{kg} / \mathrm{m}^{2}\right)$ & $26.6(3.8)$ & $26.6(3.4)$ & $27.2(4.7)$ & $26.9(4.6)$ \\
\hline \multicolumn{5}{|l|}{ Categorical variables } \\
\hline \multicolumn{5}{|l|}{ Smoking: } \\
\hline Current & 45.1 & 21.0 & 25.1 & 15.2 \\
\hline Former & 39.3 & 60.9 & 24.9 & 35.2 \\
\hline Never & 15.6 & 18.0 & 50.0 & 49.6 \\
\hline \multicolumn{5}{|l|}{ Alcohol: } \\
\hline 0 units/week & 25.8 & 32.6 & 58.6 & 58.2 \\
\hline I-13 units/week & 47.9 & 43.6 & 36.5 & 38.3 \\
\hline 14-20 units/week & 12.7 & 12.8 & 3.6 & 2.3 \\
\hline$>20$ units/week & 13.6 & 11.0 & 1.3 & 1.3 \\
\hline \multicolumn{5}{|l|}{ History of: } \\
\hline Diabetes & 14.7 & 10.4 & 10.5 & 6.9 \\
\hline Hypertension & 59.3 & 43.4 & 80.3 & 57.9 \\
\hline Angina & 0 & 59.1 & 0 & 63.1 \\
\hline Claudication & 0 & 16.0 & 0 & 14.2 \\
\hline MI & 0 & 36.9 & 0 & 21.5 \\
\hline Stroke & 0 & 9.4 & 0 & 9.0 \\
\hline TIA & 0 & 16.8 & 0 & 18.1 \\
\hline CABG & 0 & 9.1 & 0 & 2.1 \\
\hline PTCA & 0 & 4.7 & 0 & 2.7 \\
\hline PAD surgery & 0 & 5.9 & 0 & 3.4 \\
\hline \multicolumn{5}{|l|}{ Medications } \\
\hline Beta Blockers & 19.6 & 28.8 & 26.6 & 28.6 \\
\hline ACE-Inhibitors & 15.4 & 15.9 & 17.4 & 16.5 \\
\hline A-II receptor antagonists & 1.6 & 1.2 & 2.9 & 2.0 \\
\hline Diuretics & 32.3 & 28.1 & 53.3 & 45.7 \\
\hline Calcium channel blockers & 18.4 & 34.3 & 17.6 & 34.0 \\
\hline Nitrates & 0 & 41.7 & 0 & 43.6 \\
\hline Aspirin/antiplatelets & 14.4 & 68.1 & 15.2 & 56.9 \\
\hline Anti-coagulants & 0.7 & 4.9 & 0.3 & 2.4 \\
\hline Other antihypertensives & 4.9 & 4.5 & 4.5 & 1.8 \\
\hline Other anti-arrhythmic & 1.9 & 3.8 & 1.7 & 3.9 \\
\hline Other anti-anginals & 0 & 1.3 & 0 & 1.8 \\
\hline \multicolumn{5}{|l|}{ Blood glucose lowering: } \\
\hline insulin & 1.2 & 0.5 & 1.1 & 0.7 \\
\hline oral hypoglycaemics & 7.4 & 6.7 & 6.5 & 3.4 \\
\hline
\end{tabular}

tion of alcohol was more frequent in males, with approximately $12 \%$ of males consuming more than 20 units of alcohol per week. Fifty-nine percent of men and $80 \%$ of women had a history of hypertension in the primary prevention cohort, and the prevalence of diabetes ranged from $6.9 \%-14.7 \%$ across the four subgroups. In the secondary prevention group, the most prevalent indication of vascular disease was a diagnosis of stable angina, with approximately $60 \%$ having this condition. The next most common vascular conditions were a history of myocardial infarction and a history of transient ischaemic attack and stroke. The use of beta blockers, calcium channel blockers, ACE inhibitors, diuretics and nitrates reflects the high percentages of subjects who had a history of hypertension 
Table 4: Baseline ECG characteristics. Data shown are \% of randomised subjects within each column.

\begin{tabular}{|c|c|c|c|c|c|}
\hline \multirow[t]{2}{*}{ Description } & \multirow[t]{2}{*}{ Minneosta Codes } & \multicolumn{2}{|c|}{ Men } & \multicolumn{2}{|c|}{ Women } \\
\hline & & Primary & Secondary & Primary & Secondary \\
\hline Subjects(\%) & & $1345(23.2)$ & $1459(25.1)$ & $1894(32.6)$ & $1106(19.1)$ \\
\hline Myocardial infarction - Definite & $1-1$ & 4.2 & 14.2 & 2.8 & 6.3 \\
\hline Myocardial infarction - Probable & I-2 (except I-2-8) & 4.0 & 9.6 & 3.6 & 4.8 \\
\hline Myocardial infarction - Possible & $1-3$ & 7.4 & 9.8 & 7.7 & 7.5 \\
\hline Left ventricular hypertrophy - Definite & $3-I$ and at least one of $(4-I, 4-2,5-I, 5-2)$ & 3.2 & 3.4 & 3.1 & 6.1 \\
\hline Left ventricular hypertrophy - Possible & $\begin{array}{l}3-1 \text { and }(4-3 \text { and/or } 5-3) \text { or } 3-3 \text { and at least } \\
\text { one of }(4-1,4-2,4-3,5-1,5-2,5-3)\end{array}$ & 2.6 & 3.1 & 5.1 & 4.7 \\
\hline Myocardial ischaemia - Probable & $\begin{array}{l}(4-1 \text { and/or } 4-2) \text { and at least one of }(5-1,5-2 \\
\text { or 5-3) }\end{array}$ & 1.8 & 2.9 & 3.1 & 4.3 \\
\hline Myocardial ischaemia - Possible & $5-1$ or $5-2$ & 1.9 & 2.4 & 2.1 & 4.5 \\
\hline Non-specific T-wave changes & $5-3$ & 7.9 & 7.3 & 10.2 & 13.1 \\
\hline RVH Possible & $3-2$ & 0.1 & 0 & 0.2 & 0.1 \\
\hline Left axis deviation & $2-1$ & 10.6 & 9.0 & 8.0 & 8.1 \\
\hline Right axis deviation & $2-2$ or $2-3$ & 0.5 & 0.6 & 0.3 & 0.3 \\
\hline Left bundle branch block & $7-1-1$ & 1.4 & 2.6 & 2.2 & 3.0 \\
\hline Right bundle branch block & $7-2-1$ or $7-8$ & 7.0 & 6.5 & 2.4 & 2.3 \\
\hline Intraventricular conduction disturbances & $7-4$ & 2.8 & 7.6 & 1.6 & 3.3 \\
\hline
\end{tabular}

Notes : the characteristics are coded according to the following hierarchies: (i) In the myocardial infarction categories, a subject is included only once in the category corresponding to the most significant code, with definite having precedence over probable and probable precedence over possible. (ii) In the left ventricular hypertrophy categories, a subject is included only once in the category corresponding to the most significant code, with definite having precedence over possible. (iii) Subjects with a code corresponding to a definite, probable or possible myocardial infarction or a definite or possible left ventricular hypertrophy are excluded from the categories corresponding to probable or possible myocardial ischaemia or non-specific T-wave change. (iv) In the categories for myocardial ischaemia and non-specific T-wave changes, a subject is included only once in the category corresponding to the most significant code, with probable myocardial ischaemia having precedence over possible myocardial ischaemia which in turn has precedence over non-specific T-wave change.

and angina. Approximately $15 \%$ of subjects in primary prevention were taking aspirin or other antiplatelet treatment, as were $68 \%$ of men and $57 \%$ of women in secondary prevention.

The Minnesota Codes from the baseline ECGs were utilised to classify ECGs into more descriptive terms such as myocardial infarction, left ventricular hypertrophy, and myocardial ischaemia. Table 4 shows the mapping that was used for this purpose.

The average lipid profiles of the four main subgroups are given in Table 5. As would be expected in an older population, women have higher total cholesterol, LDL cholesterol, and HDL cholesterol levels than men. However, there are not substantial differences between the subject groups included on the basis of primary or secondary prevention.

An important contribution of the PROSPER study will relate to evaluation of the effect of pravastatin on cognitive decline, activities of daily living, and use of health care resources. Table 6 provides an assessment of cognitive function, activities of daily living, and resource utilisation. Data are given for the MMSE and the Barthel and IADL questionnaires, on living status, use of care facilities (home help, meals on wheels, and district nurses), on recent use of general practitioner, outpatient, and day hospital services. There are no important differences in any of these measures between the subjects recruited on the basis of primary or secondary prevention. This may, in part, be explained by the fact that all subjects were required to have an MMSE score > 24 at baseline. The only obvious gender difference is that men (25\%) are significantly less likely to be living at home on their own than women (54\%).

\section{Discussion}

In the five previously published major trials of statins, namely the Simvastatin Scandinavian Survival Study (4S), the West of Scotland Coronary Prevention Study (WOSCOPS), the Coronary And Recurrent Events study (CARE), the Long-term Intervention with Pravastatin in Ischaemic Disease study (LIPID), and the Air Force/Texas Coronary Atherosclerosis Prevention Study (AFCAPS/TexCAPS) [1-5], the average ages at baseline were 58, 55, 59, 62 , and 58 years, respectively. Furthermore, in these studies only $19 \%, 0 \%, 14 \%, 17 \%$, and $15 \%$, respectively, were women. PROSPER recruited a completely different population, for which data on the clinical efficacy of statin 
Table 5: Baseline total, LDL, HDL and VLDL cholesterol and triglycerides for randomised subjects. Data are mean (SD). All units are $\mathrm{mmol} / \mathrm{l}$.

\begin{tabular}{lcccc}
\hline & & Men & & Women \\
& Primary & Secondary & Primary & Secondary \\
\hline & & & & \\
Subjects(\%) & & & $1894(32.6)$ & $1106(19.1)$ \\
Total Cholesterol & $1345(23.2)$ & $1459(25.1)$ & $5.97(0.89)$ & $6.03(0.91)$ \\
LDL Cholesterol & $5.30(0.79)$ & $5.39(0.79)$ & $3.96(0.82)$ & $4.05(0.81)$ \\
HDL Cholesterol & $3.52(0.72)$ & $3.63(0.72)$ & $1.38(0.36)$ & $1.35(0.34)$ \\
VLDL Cholesterol & $1.22(0.33)$ & $1.14(0.30)$ & $0.62(0.35)$ & $0.63(0.38)$ \\
Triglyceride & $0.57(0.33)$ & $0.62(0.38)$ & $1.58(0.66)$ & $1.61(0.70)$ \\
& $1.43(0.69)$ & $1.55(0.76)$ & & \\
\hline
\end{tabular}

Table 6: Baseline living status, use of care facilities, and GP, out-patient and day-hospital visits and assessment of activities of daily living scores (Barthel and IADL).

\begin{tabular}{|c|c|c|c|c|c|}
\hline \multirow[t]{2}{*}{ Variable } & & \multicolumn{2}{|c|}{ Men } & \multicolumn{2}{|c|}{ Women } \\
\hline & & Primary & Secondary & Primary & Secondary \\
\hline Subjects $[N(\%)]$ & & $1345(23.2)$ & $1459(25.1)$ & $1894(32.6)$ & $1106(19.1)$ \\
\hline \multicolumn{6}{|c|}{ Assessments of activities of daily living [mean(SD)] } \\
\hline Barthel & & $19.9(0.5)$ & $19.8(0.7)$ & $19.7(0.8)$ & $19.6(1.0)$ \\
\hline IADL & & $13.7(0.8)$ & $13.6(1.1)$ & $13.7(0.9)$ & $13.4(1.2)$ \\
\hline \multicolumn{6}{|l|}{ MMSE (Visit AI) [mean(SD)] } \\
\hline Score & & $28.1(1.5)$ & $28.0(1.5)$ & $28.0(1.6)$ & $28.0(1.5)$ \\
\hline \multicolumn{6}{|l|}{ Living status [\% of column total] } \\
\hline Home alone & & 25.6 & 23.6 & 53.8 & 55.2 \\
\hline Home not alone & & 73.2 & 74.4 & 43.6 & 41.0 \\
\hline Not home & & 1.2 & 2.1 & 2.6 & 3.9 \\
\hline \multicolumn{6}{|c|}{ Use of care facilities [\% of column total] } \\
\hline \multirow[t]{3}{*}{ Home help (days/week) } & 0 days & 93.5 & 91.8 & 91.4 & 86.4 \\
\hline & I day & 5.2 & 5.6 & 6.6 & 9.2 \\
\hline & $>1$ day & 1.3 & 2.7 & 2.0 & 4.3 \\
\hline \multirow[t]{2}{*}{ Meals on wheels (days/week) } & 0 days & 98.4 & 98.5 & 98.4 & 98.6 \\
\hline & $\geq$ I days & 1.6 & 1.5 & 1.6 & 1.5 \\
\hline \multirow[t]{2}{*}{ District Nurse (days/month) } & 0 days & 99.4 & 99.6 & 99.3 & 98.4 \\
\hline & $\geq$ I days & 0.6 & 0.4 & 0.7 & 1.6 \\
\hline \multicolumn{6}{|c|}{ GP and hospital visits previous 3 months [\% of column total] } \\
\hline \multirow[t]{3}{*}{ GP Surgery visits } & 0 & 39.4 & 36.5 & 33.8 & 33.5 \\
\hline & I & 29.7 & 32.0 & 32.0 & 27.2 \\
\hline & $>1$ & 30.7 & 31.5 & 34.2 & 39.2 \\
\hline \multirow[t]{3}{*}{ GP Home visits } & 0 & 97.7 & 96.2 & 96.0 & 93.6 \\
\hline & 1 & 1.6 & 2.9 & 2.6 & 4.2 \\
\hline & $>1$ & 0.7 & 0.9 & 1.4 & 2.2 \\
\hline \multirow[t]{3}{*}{ Outpatient hospital } & 0 & 83.1 & 79.4 & 84.3 & 77.6 \\
\hline & 1 & 13.5 & 15.2 & 12.4 & 18.2 \\
\hline & $>1$ & 3.4 & 5.4 & 3.3 & 4.3 \\
\hline \multirow[t]{3}{*}{ Day hospital } & 0 & 98.7 & 98.9 & 98.6 & 98.0 \\
\hline & 1 & 1.1 & 1.0 & 1.3 & 1.7 \\
\hline & $>1$ & 0.2 & 0.1 & 0.1 & 0.3 \\
\hline
\end{tabular}


treatment are scarce. The PROSPER population is characterised by an average age of 75 years and includes $52 \%$ women. Subjects in both primary and secondary prevention were recruited across a wide spectrum of baseline cholesterol levels, thus providing a wealth of new information on the benefits of statin treatment in a group of elderly subjects with a very high risk of coronary and cerebrovascular events. This population reflects the older patients in general practice, for whom statin treatment might be considered. As the elderly are taking a wide range of prescription medications, with many taking multiple concomitant treatments, PROSPER will provide an opportunity for a rigorous assessment of the safety of pravastatin treatment.

It is well known that the prevalence of ECG abnormalities increases with age (Ashley et al [8]), a factor that should be considered when examining the prevalence of baseline ECG abnormalities in PROSPER. Furberg et al. [9] reported on major ECG abnormalities in a random sample of 5,150 individuals aged 65 years and older. Although numbers were small in those over 80 years, the prevalence of any major ECG abnormality (myocardial infarction, LVH, isolated ST-T changes, ventricular conduction defect, atrial fibrillation, and first degree AV block) rose from $37.9 \%$ in men aged 65 to 69 years with coronary artery disease and hypertension to $61.1 \%$ in men over 85 years. Corresponding figures for women were $25.8 \%$ to $38.8 \%$. It is against this background that the approximate $25 \%$ prevalence of myocardial infarction, $\mathrm{LVH}$, and myocardial ischaemia in both genders of the primary prevention group forin this study needs to be considered. A small number of individuals $(2.0 \%)$ had both myocardial infarction and left ventricular hypertrophy. In every major category, as expected, the prevalence of abnormalities in the secondary prevention group was higher than in the primary prevention group, while the prevalence of $\mathrm{LVH}$ in women was higher than in men, as noted by Furberg et al. [9]. The reverse was true for myocardial infarction. In the PROSPER sample, a history of myocardial infarction in $36.9 \%$ of males and $21.5 \%$ of females closely parallels the ECG findings of infarction in $33.6 \%$ of males and $18.6 \%$ of females in the secondary prevention group.

A particularly novel aspect of the study is the collection of detailed longitudinal data on various elements of cognitive function, activities of daily living, and health care resource utilisation. These data will add significantly to the information collected on clinical events by providing a detailed profile of the PROSPER recruits, with regard to important aspects of quality of life in the elderly, and the cost-effectiveness of treatment with pravastatin. A more detailed analysis of the baseline cognitive status of study subjects, and a design paper for the proposed economic analysis will be published elsewhere. Recently [10], the
WOSCOPS investigators published findings suggesting a link between treatment with pravastatin and prevention of diabetes. PROSPER will provide an opportunity to confirm this finding. The study has achieved its first goal of recruiting more than 5,500 high-risk men and women, over the age of 70 years. Follow-up is ongoing, and the study should complete all subject visits in the first half of 2002. The main results will be available in the fourth quarter of 2002 .

\section{Competing Interests}

The authors of this paper disclose their affiliations over the last five years with Bristol-Myers Squibb (BMS), Astra Zeneca (AZ), Sankyo (S), Schering Plough (SP), GlaxoSmithKline (GSK), Shionogi (Sh), Pfizer (P), Merck Sharp \& Dohme (MSD), and Novartis $(\mathrm{N})$. These relate to personal or institutional-affiliated receipt of, income in the areas: (a) Research grants, (b) honoraria, (c) Consultant fees, as follows: IF [BMS(a,b,c), AZ(b), S(a,b)], JN [BMS(a,b), S(a)], RGJW [BMS(a,b)], AEM [BMS(a)], GJB [BMS $(\mathrm{a}, \mathrm{b})]$, JWJ $[\operatorname{BMS}(\mathrm{a}, \mathrm{b})], \operatorname{AML}[\operatorname{BMS}(\mathrm{a}, \mathrm{b})], \operatorname{ELEMB}$ $[\operatorname{BMS}(a, b)], \quad C P \quad[B M S(a, b, c), A Z(a, b, c), \quad S P(a, b)], A G$ [BMS(a,b), AZ(b), S(b), MSD(b)], PM [BMS(a,b,c)], DJS [BMS(a)], JS [BMS $(a, b, c), \operatorname{AZ}(b, c), \operatorname{SP}(b, c), \operatorname{GSK}(b, c)$, Sh(c)], SMC [BMS $(a, b, c), A Z(b), P(a, b), \operatorname{MSD}(b)], M B M$ [BMS $(a, b, c), \operatorname{MSD}(b, c), P(a, b)], B B[B M S(b, c), P(a, b)$, $\mathrm{AZ}(\mathrm{b}, \mathrm{c}), \mathrm{N}(\mathrm{a}, \mathrm{b}, \mathrm{c})], \quad \mathrm{IP}[\mathrm{BMS}(\mathrm{b})], \mathrm{MH} \quad[\mathrm{BMS}(\mathrm{b})], \mathrm{CT}$ [BMS(b)], BJS [BMS(b)].

\section{Appendix \\ Membership of Committees}

Executive Committee

Cork - Professor Michael B Murphy (Principal Investigator), Dr Brendan M Buckley (Pharmacology \& Therapeutics), Dr Michael Hyland (Geriatrics), Professor Ivan J Perry (Epidemiology and Public Health,Glasgow - Professor Jim Shepherd (Chairman/Principal Investigator), Professor Chris J Packard (Study Director), Dr Allan Gaw (Deputy Study Director), Professor Stuart M Cobbe (Cardiology), Professor David J Stott (Geriatrics), Leiden - Dr Gerard J Blauw (Principal Investigator), Professor Rudi G J Westendorp (Gerontology \& Geriatrics), Dr A Margot Lagaay (Gerontology \& Geriatrics), Dr Edward L E M Bollen (Neurology), Minerva - Mr Melvyn J Percy (Non-Voting Member), Data Centre - Professor Ian Ford, ECG Core Laboratory - Professor Peter W Macfarlane (Co-ordination), Non-voting sponsor representative - Dr Rene Belder (Bristol-Myers Squibb)

\section{Study Co-ordinating Centres}

Cork Admin Centre - Dr Brendan M Buckley, Glasgow Admin Centre - Professor Chris J Packard (Study Director), Dr Allan Gaw (Deputy Study Director), Ms Christine McLaughlin, Leiden Admin Centre - Dr Edward L E M Bollen, Population screening and Site management - 
Minerva: Mr Melvyn J Percy, Mr David McGowan, IndependentData and Statistical Centre - Robertson Centre for Biostatistics, University of Glasgow: Professor Ian Ford, Ms Elizabeth Anderson, Mr John Norrie (Study Statistician), Ms Sharon Kean, Ms Catherine Innes

\section{Data and Safety Monitoring Committee}

Dr William Virgil Brown (Chairman, Atlanta, Georgia, USA), Dr Hans-Christoph Diener (Essen, Germany), Professor John Feely (Dublin, Ireland), Professor Pieter A van Zwieten (Amsterdam, Netherlands), Dr Stuart Pocock (London, England, UK), Dr Thomas Pearson (Rochester, New York, USA), Professor Ian Ford (non-voting, Glasgow, Scotland, UK)

\section{Endpoint Committee}

Glasgow - Professor Stuart M Cobbe (Chairman, Cardiology), Professor David J Stott (Geriatrics), Professor Peter W Macfarlane (Cardiology - Non-Voting), Cork - Dr Brian Sweeney (Neurology), Dr Cillian Twomey (Geriatrics), Leiden - Dr J Wouter Jukema (Cardiology), Prof A Edo Meinders (Internal Medicine \& Geriatrics)

\section{Publications Committee}

Cork - Professor Michael B Murphy (Principal Investigator), Dr Brendan M Buckley, Dr Michael Hyland, Professor Ivan J Perry, Dr Brian Sweeney, Dr Cillian Twomey, Glasgow - Professor Jim Shepherd (Chairman/Principal Investigator), Professor Stuart M Cobbe, Professor Ian Ford, Dr Allan Gaw, Professor Peter W Macfarlane, Mr J. Norrie, Professor Chris J Packard, Professor David J Stott, Leiden - Dr Gerard J Blauw (Principal Investigator), Dr Edward L E M Bollen, Dr J Wouter Jukema, Dr A Margot Lagaay, Prof A Edo Meinders, Professor Rudi G J Westendorp.

\section{References}

I. Scandinavian Simvastatin Survival Study Group: Randomised trial of cholesterol lowering in 4444 patients with coronary heart disease: the Scandinavian Simvastatin Survival Study (4S). Lancet 1994, 344:1383-1389

2. Shepherd J, Cobbe SM, Ford I, for the West of Scotland Coronary Prevention Study Group, et al: Prevention of coronary heart disease with pravastatin in men with hypercholesterolemia. New Engl J Med 1995, 333: I 30 I-1 307

3. Sacks FM, Pfeffer MA, Moye LA, et al: The Effect of pravastatin on coronary events after myocardial infarction in patients with average cholesterol levels. New Engl J Med 1996, 335:100I-1009

4. Long-term intervention with Pravastatin in Ischaemic Disease (LIPID) Study Group: Prevention of cardiovascular events and death with pravastatin in patients with coronary heart disease and a broad range of initial cholesterol levels. New Engl ] Med 1998, 339:1349-1357

5. Downs JR, Clearfield M, Weis $\mathrm{S}$, for the AFCAPS/TexCAPS Research Group, et al: Primary prevention of acute coronary events with lovastatin in men and women with average cholesterol levels: results of AFCAPS/TexCAPS. JAMA 1998, 279:16151622

6. Shepherd J, Blauw GJ, Murphy MB, on behalf of the PROSPER Study Group, et al: The Design of a Prospective Study of Pravastatin in the Elderly at Risk (PROSPER). Am J Cardiol 1999, 84: I 1921197
7. Macfarlane PW, Latif S: Automated serial ECG comparison based on the Minnesota Code. J. Electrocardiol 1996, 29(Suppl):29-34

8. Ashley EA, Raxwal VK, Froelicher VF: The prevalence and prognostic significance of electrocardiographic abnormalities. Current problems in Cardiology. 2000, 25: I-72

9. Furberg CD, Manolio TA, Psaty BM, et al: Major electrocardiographic abnormalities in persons aged 65 years and over (Cardiovascular Health Study). Am / Cardiol 1992, 69:1 329-1 335

10. Freeman DJ, Norrie J, Sattar N, et al: Pravastatin and the Development of Diabetes Mellitus: Evidence for a protective treatment effect in the West of Scotland Coronary Prevention Study. Circulation. 200I, 103:357-362

\footnotetext{
Publish with BioMed Central and every scientist can read your work free of charge

"BioMedcentral will be the most significant development for disseminating the results of biomedical research in our lifetime." Paul Nurse, Director-General, Imperial Cancer Research Fund

Publish with BMC and your research papers will be:

- available free of charge to the entire biomedical community

- peer reviewed and published immediately upon acceptance

- cited in PubMed and archived on PubMed Central

- yours - you keep the copyright 